\title{
CHIRAL FOUR MEMBERED CYCLIC NITRONES; ASYMMETRIC INDUCTION IN THE (4+2)-CYCLOADDITION REACTION OF CHIRAL YNAMINES AND NITROALKENES
}

\author{
P.A. van Elburg, G.W.N. Honig, and D.N. Reinhoudt ${ }^{*}$ \\ Laboratory of Organic Chemistry, University of Twente, Enschede, The \\ Netherlands
}

\begin{abstract}
Chiral four-membered cyclic nitrones were synthesized by the asymmetric (4+2)-cycloaddition of nitroalkenes 1 and chiral ynamines 2 . The subsequent stereoselective addition of nucleophiles to these nitrones enabled the synthesis of chiral $\mathrm{N}$-hydroxyazetidines.
\end{abstract}

Asymmetric cycloadditions become increasingly useful in controlling the absolute stereochemistry during the formation of more than one bond in one reaction. 1

Previously we have reported the stereoselective synthesis of four-membered cyclic nitrones by the cycloaddition of nitroalkenes 1 and ynamines $2 .^{2}$ In this reaction two chiral carbon centers are formed of which the stereochemistry at $\mathrm{C}-2$ is determined by the stereochemistry at $\mathrm{C}-3$ in the intermediate nitron ester 3. Upon ring contraction only two enantiomeric nitrones $4(2 R, 3 R)$ and $5(2 S, 3 S)$ are formed in equal amounts.

We anticipated that a chiral $\underline{N}, \underline{N}$-dialkylamino group in the ynamines 2 might cause asymmetric induction in the cycloaddition with prochiral nitroalkenes, resulting in a preferential formation of one of the enantiomeric nitrones 4 or 5. In this paper we describe the first synthesis of chiral ynamines and their use in the asymmetric synthesis of four-membered cyclic nitrones and 1-hydroxyazetidines.

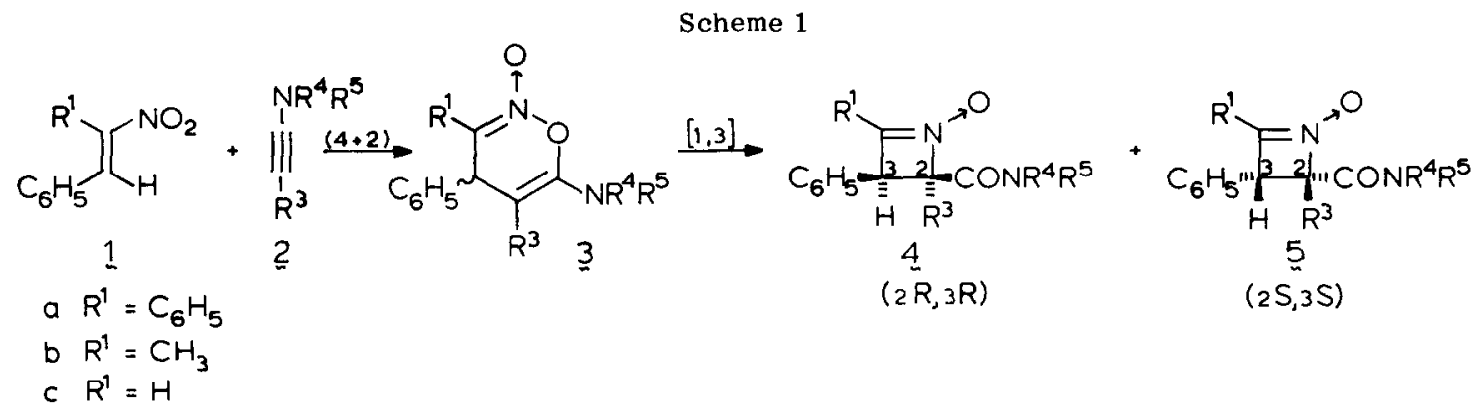

The racemic ynamine $2 a$ was synthesized from ( + )-2-methylpyrrolidine and 1-ethoxy-1-butyne in analogy with standard procedures ${ }^{3}$ and was obtained in $61 \%$ yield [bp 50-52 ${ }^{\circ} \mathrm{C}(5 \mathrm{~mm})$; mass spectrum, $\underline{m / e} 137.120\left(\mathrm{M}^{+}\right.$, calcd for $\left.\left.\mathrm{C}_{9} \mathrm{H}_{15} \mathrm{~N}: 137.120\right)\right]$. Similarly, racemic 2,5-dimethyl-1-(phenylethynyl)pyrrolidine (2b) was prepared from the $\mathrm{HCl}-\mathrm{salt}$ of trans-( +2$)-2,5$-dimethylpyrrolidine 4 and (chloroethynyl)benzene in a yield of 168 in anglogy with the synthesis of ynamine $2 a$ (Chart 1 ).

In analogy with the synthesis of compound $2 a$, the chiral ynamine $2 c$ was obtained from (S)-(-)-2-(methoxymethyl) pyrrolidine and 1-ethoxy-1-butyne in 528 yield $\left[[\alpha]_{D}{ }^{25}-47.1\right.$ (benzene, c: 1.53); bp 60-62 ${ }^{\circ} \mathrm{C}(0.02 \mathrm{~mm})$; mass spectrum, m/e $167.131\left(\mathrm{M}^{+}\right.$, calcd for $\left.\left.\mathrm{C}_{10} \mathrm{H}_{17} \mathrm{NO}: 167.131\right)\right]$. 
Reaction of the lithium salt of (S) ( - )-2-(methoxymethyl)pyrrolidine with (chloroethynyl)benzene afforded the ynamine $2 \mathrm{~d}$ in $62 \frac{\circ}{\circ}$ yield $\left[[\alpha]_{\mathrm{D}}{ }^{25}-74.3\right.$ (benzene, c: 1.75$) ;$ bp $105-108{ }^{\circ} \mathrm{C}(0.002 \mathrm{~mm})$; mass spectrum, m/e $215.132\left(\mathrm{M}^{+}\right.$, calcd for $\left.\left.\mathrm{C}_{14} \mathrm{H}_{17} \mathrm{NO}: 215.131\right)\right]$. Both ynamines 2c and 2d were synthesized without racemization in optical yields of more than $95 \% 5$

Chart 1

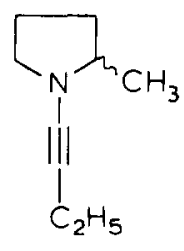

$2 a$

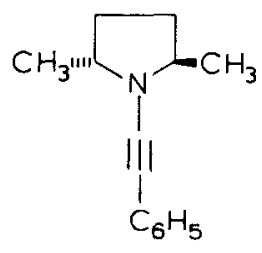

( $₫) 2 b$

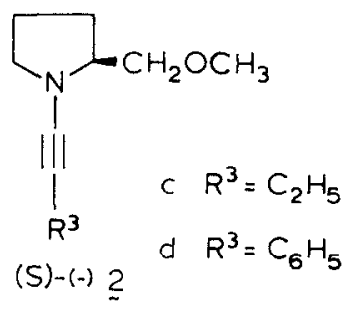

When the racemic ynamine $2 a$ was reacted with nitroalkene $1 a,{ }^{6}$ two diastereomeric nitrones were isolated in a total yield of $61 \%, 7$ and in a ratio of $66: 34$. The diastereomers were separated by preparative TLC [aluminum oxide; eluent: chloroform/diethyl ether/petroleum ether bp 40-60 ${ }^{\circ} \mathrm{C} 1: 1: 1(\mathrm{v} / \mathrm{v})$ ] giving a fast

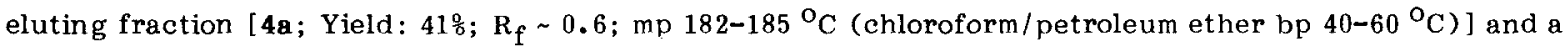
slow eluting fraction [5a; Yield: 20; $\mathrm{R}_{\mathrm{f}} \sim 0.2 ; \mathrm{mp} \mathrm{180-182}{ }^{\circ} \mathrm{C}$ (chloroform/diisopropyl ether)]. Mainly on the basis of the ${ }^{1} \mathrm{H}$-NMR absorptions of the methyl groups of the pyrrolidinyl substituent in both isomers we assigned the $\left(2^{\prime} \mathrm{R}, 2 \mathrm{R}, 3 \mathrm{R}\right) / /\left(2^{\prime} \mathrm{S}, 2 \mathrm{~S}, 3 \mathrm{~S}\right)$ stereochemistry to the racemic nitrone $4 \mathrm{a}(\delta 0.87, \mathrm{bd}, 3 \mathrm{H})$ which is formed in excess and the $\left(2^{\prime} \mathrm{R}, 2 \mathrm{~S}, 3 \mathrm{~S}\right) / /\left(2^{\prime} \mathrm{S}, 2 \mathrm{R}, 3 \mathrm{R}\right)$ stereochemistry to the isomer $5 \mathrm{a}(\delta 0.82, d$, $3 \mathrm{H}$ ) (Chart 2).

When racemic ynamine $\mathbf{2 b}$ was reacted with nitroalkene $1 \mathbf{a}$, two diastereomeric nitrones were isolated in a yield of $43 \%$ (ratio $64: 36){ }^{7}$ The diastereomers were separated by preparative TLC [silica gel; eluent: chloroform/petroleum ether bp $40-60{ }^{\circ} \mathrm{C} 1: 2(\mathrm{v} / \mathrm{v}) \mathrm{l}$. The fast eluting fraction (4d; Yield: $28 \frac{\mathrm{o}}{\mathrm{o}} ; \mathrm{R}_{\mathrm{f}} \sim 0.5$ ) shows in the ${ }^{1} \mathrm{H}-\mathrm{NMR}$ spectrum two doublets at $\delta 0.89$ and $0.57(\mathrm{~J}=6.3 \mathrm{~Hz}, 3 \mathrm{H})$. The slow eluting fraction (5d; Yield: $16 \%$ \% $\mathrm{R}_{\mathrm{f}} \sim 0$ ) shows in the ${ }^{1} \mathrm{H}$ NMR spectrum two doublets at $\delta 0.70$ and $0.03(\mathrm{~J}=6.3 \mathrm{~Hz}, 3 \mathrm{H})$ (Chart 2). Molecular models of both possible cis-substituted diastereomeric nitrones $4 d$ and $5 d$, indicate that in the nitrone with the $\left(2^{\prime} \mathrm{R}, 5^{\prime} \mathrm{R}, 2 \mathrm{R}, 3 \mathrm{~S}\right) / /\left(2^{\prime} \mathrm{S}, 5^{\prime} \mathrm{S}, 2 \mathrm{~S}, 3 \mathrm{R}\right)$ stereochemistry only one methyl group of the pyrrolidinyl group may be strongly shielded in the ${ }^{1} \mathrm{H}-\mathrm{NMR}$ spectrum due to shielding by the phenyl group at $\mathrm{C}-3$. Therefore we assigned to the diastereomeric nitrone $4 \mathrm{~d}$, which is formed in excess, the $\left(2^{\prime} R, 5^{\prime} R, 2 S, 3 R\right) / /\left(2^{\prime} S, 5^{\prime} S, 2 R, 3 S\right)$ stereochemistry and to the isomer $5 d$ the $\left(2^{\prime} R, 5^{\prime} R, 2 R, 3 S\right) / /$ $\left(2^{\prime} \mathrm{S}, 5^{\prime} \mathrm{S}, 2 \mathrm{~S}, 3 \mathrm{R}\right)$ stereochemistry.

Reaction of racemic ynamine $2 b$ with nitroalkene $1 b^{8}$ gave only one diastereomeric nitrone (5e) in a yield of $40 \%$ (d.e. $>95 \%$ based on NMR spectroscopy). This product shows in the ${ }^{1} \mathrm{H}-\mathrm{NMR}$ spectrum two doublets at $\delta 0.68$ and $-0.08(J=6.3 \mathrm{~Hz}, 3 \mathrm{H})$ for the methyl groups of the pyrrolidinyl substituent. Reaction of ynamine $\mathbf{2 b}$ with nitroalkene $1 \mathbf{c}^{\mathbf{9}}$ also afforded only one diastereomeric nitrone (5f) in a yield of 28 응 $\underline{\text { d.e. }} \geqslant 95 \%$ based on NMR spectroscopy). The ${ }^{1} \mathrm{H}-\mathrm{NMR}$ spectrum of $5 \mathrm{f}$ exhibits two doublets at $\delta 0.57$ and $-0.20(\mathrm{~J}=6.3 \mathrm{~Hz}, 3 \mathrm{H})$ for the methyl groups of the pyrrolidinyl group. On the basis of the large difference of the chemical shifts of the methyl groups in the nitrones $5 \mathbf{e}$ and $\mathbf{5} f$, as was also observed in nitrone 5d, we assigned the $\left(2^{\prime} R, 5^{\prime} R, 2 R, 3 S\right) / /\left(2^{\prime} S, 5^{\prime} S, 2 S, 3 R\right)$ stereochemistry to the nitrones $5 \mathbf{e}$ and $5 f$. 


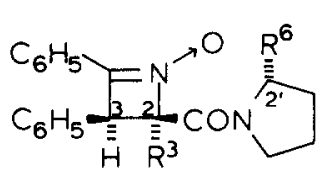

4

a $\left(2^{\prime} R, 2 R, 3 R\right) /\left(2^{\prime} S, 2 S, 3 S\right)$

b $\left(2^{\prime} S, 2 R, 3 R\right)-(+)$

c. $\left(2^{\prime} S, 2 S, 3 R\right)-(-)$
Chart 2

$$
\begin{aligned}
& R^{3}=\mathrm{C}_{2} \mathrm{H}_{5} ; R^{6}=\mathrm{CH}_{3} \\
& R^{3}=\mathrm{C}_{2} \mathrm{H}_{5} ; \mathrm{R}^{6}=\mathrm{CH}_{2} O C \mathrm{H}_{3} \\
& R^{3}=\mathrm{C}_{6} \mathrm{H}_{5} ; R^{6}=\mathrm{CH}_{2} O C \cdot \mathrm{H}_{3}
\end{aligned}
$$

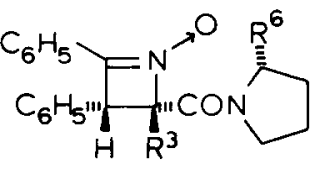

5

a $\left(2^{\prime} R, 2 S, 3 S\right) /\left(2^{\prime} S, 2 R, 3 R\right)$

b $\left(2^{\prime} S, 2 S, 3 S\right)-(-)$

c $(2$ 'S, 2R, 3S) $-(+)$

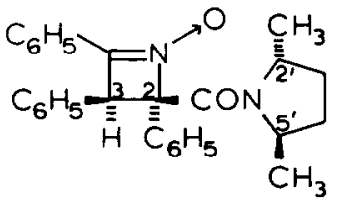

4

$\left(2^{\prime} R, 5^{\prime} R, 2 S, 3 R\right) /\left(2^{\prime} S, 5^{\prime} S, 2 R, 3 S\right)$

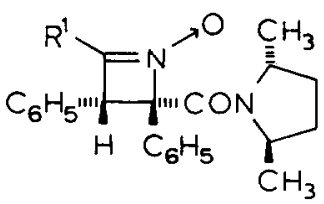

5 d $R^{1}=\mathrm{C}_{6} \mathrm{H}_{5}$

e $R^{1}=H$

f $R^{\prime}=\mathrm{CH}_{3}$

When the optically pure ynamine $2 \mathrm{c}$ was reacted with nitroalkene 1a a mixture of two diastereomeric nitrones was isolated in a total yield of $51 \%,{ }^{7}$ and in a ratio of $73: 27$. Both diastereomers were separated by preparative TLC [aluminum oxide; eluent: acetone/petroleum ether bp $40-60{ }^{\circ} \mathrm{C} 3: 2(\mathrm{v} / \mathrm{v})$ ], giving a fast eluting fraction [4b; Yield 33o; $[\alpha]_{\mathrm{D}}{ }^{25}+47.8$ (chloroform, c: 0.65 ); $\mathrm{R}_{\mathrm{f}} \sim 0.4 ; \mathrm{mp} 177-178{ }^{\circ} \mathrm{C}$ (choroform/diisopropyl ether)] and a slow eluting fraction [5b; Yield: $11 \%$; $[\alpha]_{D}{ }^{25}-109.1$ (chloroform, c: 0.71 ); $\mathrm{R}_{\mathrm{f}}-0.3 ; \mathrm{mp} 170-173^{\circ} \mathrm{C}$ (chloroform/diisopropyl ether)] (Chart 2). From molecular models and from comparison of the NMR data with those of the nitrones $4 a$ and $5 a$ we concluded that nitrone $4 b$, which is formed in a d.e. of $46 \%$, has the $\left(2^{\prime} \mathrm{S}, 2 \mathrm{R}, 3 \mathrm{R}\right)$ stereochemistry and that nitrone $5 \mathrm{~b}$ has the $\left(2^{\prime} \mathrm{S}, 2 \mathrm{~S}, 3 \mathrm{~S}\right)$ stereochemistry.

When the optically active ynamine $2 \mathrm{~d}$ was reacted with nitroalkene $1 \mathrm{a}$ for $3 \mathrm{~h}$, two diastereomeric nitrones were isolated in a ratio of $28: 68$ and in a total yield of $52 \%{ }^{7}$ Separation of the nitrones by column chromatography gave nitrone 4c [Yield: 22\%; $[\alpha]_{\mathrm{D}}{ }^{25}-416.7$ (chloroform, c: 0.58); $\mathrm{mp}>240{ }^{\circ} \mathrm{C}$ (chloroform/diisopropyl ether); mass spectrum, $\underline{m} / \mathrm{e} 440.209\left(\mathrm{M}^{+}\right.$, calcd for $\left.\left.\mathrm{C}_{28} \mathrm{H}_{28} \mathrm{~N}_{2} \mathrm{O}_{3}: 440.210\right)\right]$. We assigned to nitrone $4 \mathrm{c}$, which was formed in a d.e. of $41 \%$, the (2'S, $\mathrm{S}, 3 \mathrm{R})$ stereochemistry. Nitrone 5c [Yield 10\%; $[\alpha]_{\mathrm{D}}{ }^{25}+304.8$ (chloroform, c: 0.836 ); $\mathrm{mp}>240{ }^{\circ} \mathrm{C}$ (chloroform/diisopropyl ether); mass spectrum, m/e $440.209\left(\mathrm{M}^{+}\right.$, calcd for $\left.\left.\mathrm{C}_{28} \mathrm{H}_{28} \mathrm{~N}_{2} \mathrm{O}_{3}: 440.210\right)\right]$ was assigned the $(2$ ' $, 2 \mathrm{R}, 3 \mathrm{~S})$ stereochemistry.

Reaction of racemic nitrone $4 a$ with allylmagnesium bromide, in a mixture of diethyl ether and benzene, gave the allylsubstituted 1-hydroxyazetidine $6 \mathrm{a}$ in a yield of $208[13 \mathrm{C}-\mathrm{NMR} \delta: 170.0(\mathrm{~s}, \mathrm{C}=0), 77.1$ and $74.9(\mathrm{~s}, \mathrm{C}-4$ and $\mathrm{C}-2)$; mass spectrum, $\mathrm{m} / \mathrm{e} 404.248\left(\mathrm{M}^{+}\right.$, calcd for $\left.\mathrm{C}_{26} \mathrm{H}_{32} \mathrm{~N}_{2} \mathrm{O}_{2}: 404.246\right)$ ]. On the basis of the NMR spectra of corresponding 1-hydroxyazetidines without substituents in the pyrrolidine ring, 10 we assigned the $(2 ' R, 2 R, 3 \mathrm{~S}, 4 \mathrm{~S}) / /(2 ' \mathrm{~S}, 2 \mathrm{~S}, 3 \mathrm{R}, 4 \mathrm{R})$ stereochemistry to 1 -hydroxyazetidine $6 \mathrm{a} .11$

When the optically active nitrone $4 \mathrm{~b}$ was reacted with allylmagnesium bromide 1 -hydroxyazetidine $6 \mathrm{~b}$ was isolated in a yield of $54 \%$. $\left[[\alpha]_{\mathrm{D}}{ }^{25}-41.8\right.$; (chloroform, c: 1.58); ${ }^{13} \mathrm{C}-\mathrm{NMR} \delta: 170.4(\mathrm{~s}, \mathrm{C}=0), 76.6$ and 74.9 ( $\mathrm{s}, \mathrm{C}-4$ and $\mathrm{C}-2)$; mass spectrum, $\underline{\mathrm{m} / \mathrm{e}} 434.258\left(\mathrm{M}^{+}\right.$, calcd for $\left.\left.\mathrm{C}_{27} \mathrm{H}_{34} \mathrm{~N}_{2} \mathrm{O}_{3}: 434.257\right)\right]$ with a stereochemistry as shown in Chart $3 .^{11}$ 
Finally, when the optically active nitrone $4 \mathrm{c}$ was reacted with allylmagnesium bromide, the chiral 1 -hydroxyazetidine $6 \mathrm{c}$ was obtained in a yield of $31 \frac{\mathrm{g}}{6}\left[[\alpha]_{\mathrm{D}}{ }^{25}+74.6\right.$; (chloroform, e: 0.36 ); $13 \mathrm{C}-\mathrm{NMR} \delta$ : $170.5(\mathrm{~s}, \mathrm{C}=\mathrm{O}), 80.7$ and $76.2(\mathrm{~s}, \mathrm{C}-4$ and $\mathrm{C}-2)$; mass spectrum, m/e $482.254\left(\mathrm{M}^{+}, \mathrm{caled} \mathrm{for}_{31} \mathrm{H}_{34} \mathrm{~N}_{2} \mathrm{O}_{3}\right.$ : 482.257) 1. Comparison of the NMR spectra of $6 c$ with those of related structures, ${ }^{10}$ shows similar chemical shifts of the characteristic substituents and we assigned the $(2 ' S, 2 \mathrm{~S}, 3 \mathrm{~S}, 4 \mathrm{~S})$ stereochemistry to the optically active compound $\mathbf{6 c}$.

\section{Chart 3}

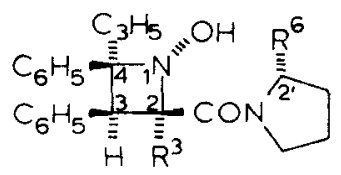

$$
\begin{aligned}
& a\left(2^{\prime} R, 2 R, 3 S, 4 S\right) / /\left(2^{\prime} S, 2 S, 3 R, 4 R\right) ; R^{3}=C_{2} H_{5} ; R^{6}=C_{3} \\
& b\left(a^{\prime} S, 2 R, 3 S 4 S\right) \cdot(-) \\
& , \mathrm{R}^{3}=\mathrm{C}_{2} \mathrm{H}_{5}, \mathrm{R}^{6}=\mathrm{CH}_{2} \mathrm{OCH}_{3} \\
& c\left(2^{\prime} S, 2 S, 3 S, 4 S\right)-(+) \\
& ; \mathrm{R}^{3}=\mathrm{C}_{6} \mathrm{H}_{5} ; \mathrm{R}^{6}=\mathrm{CH}_{2} \mathrm{OCH}_{3}
\end{aligned}
$$

In conclusion we have shown that chiral ynamines are readily available from the corresponding chiral secondary amines and the promising results in the asymmetric (4+2)-cycloaddition reactions with nitroalkenes will be further investigated and extended to other (cyclo)addition reactions of chiral ynamines.

Acknowledgement. This investigation was supported by the Netherlands Foundation for Chemical Research (SON) with financial aid from the Netherlands Organization for Advancement of Pure Research ( $\mathrm{ZWO}$.

\section{REFERENCES AND NOTES}

1. Oppolzer, W. Angew. Chem. (1984), 96, 840 .

2. Pennings, M.L.M.; Reinhoudt, D.N. J. Org. Chem. (1982), 47, 1816.

3. a Delavarenne, S.Y.; Viehe, H.G. "Chemistry of Acetylenes" (1969), Dekker, H., ed., New York. $\underline{b}$ Brandsma, I. "Preparative Acetylenic Chemistry" (1971), Elsevier, Amsterdam. c Brandsma, L.; Verkruijsse, H.D. "Synthesis of Acetylenes, Allenes and Cumulenes" (198 $\overline{1}$ ), Elsevier, Amsterdam.

4. Harding, K.E.; Burks, S.R. J. Org. Chem. (1981), $46,3920$.

5. Hydrolysis of the optically active ynamines gave the corresponding amides (from $2 c:[\alpha] 25-71.2$ (chloroform, e: 0.66); from 2d: [ a $]_{1} 25-48.8$ (chloroform, c: 1.89). The optical rotations corresponded with the rotations of the amides, prepared independently from the corresponding, optically active amines and acid chlorides.

6. Robertson, D.N. J. Org. Chem. (1960), 25, 47.

7. The isolation of the nitrones in yields lower than $60 \%$ is due to the simultaneous formation of instable $(2+2)$-cycloadducts. Pennings et al. reported the simultaneous formation of 4-nitrocyclobutenes, as the $(2+2)-c y c l o a d d u c t s$, in the reaction of ynamines and nitroalkenes (see ref. 2 ).

8. Hass, H.B.; Susie, A.G.; Heider, R.L. J.Org. Chem. (1950), $15,8$.

9. Worral, D.E. Org. Synth. (1929), 9,66.

10. Van Elburg, P.A.; Reinhoudt, D.N.; Harkema, S.; Submitted for publication.

11. a From previous work it is known that Grignard reagents add stereoselectively from the less hindered side of the four-membered ring; van Elburg, P.A.; Reinhoudt, D.N. Submitted for publication.

$\underline{b}$ From X-ray studies and NMR studies of 1-hydroxyazetidines we concluded that the hydroxyl group at the nitrogen atom is preferentially trans to the carbamoyl group at C-2; van Elburg, P.A.; Reinhoudt, D.N.; Harkema, S. Submitted for publication.

(Received in UK 21 October 1987) 